\title{
Information Commons Help Desk Transactions Study
}

by Gabrielle K. W. Wong (Ibgabi@ust.hk) Information Commons Coordinator

HKUST Library

October 2009

\begin{abstract}
With the purpose of designing a training program for a new team serving at a technology service point, the author analyzed the transactions log using a new, multi-faceted, taxonomy. The resulting list of competencies and the methodology would be useful for managers of information or learning commons.
\end{abstract}

\section{Introduction}

The impact of information and computer technology on library services has reached a new level as libraries worldwide introduce technology-rich service facilities frequently known as "commons". Computing facilities have become ubiquitous information and learning tools; this trend leads to a compelling need for academic libraries to provide and support such facilities, and thus a corresponding growth in user expectations for assistance in using them. This poses a real challenge to libraries in reference staffing and service points planning. The traditional reference service models no longer function in a commons environment.

Each library may have its own solution to address this change in service environment and concept. A highly specialized "tiered" model in which technology questions are referred to a separate help desk staffed with technicians or computer specialists is one possibility; another strategy is to integrate the technology elements into existing reference service by deploying tech-savvy paraprofessionals at service points. When discussing whether effective service delivery requires a "hybrid" support staff, or one with increasing specialized skills, Halbert states the answer at Emory University General Libraries as "a bit of both": "gaining additional knowledge broadly applicable to new technology must also be paired with relevant specialization 
in particular topics (both technical and subject-based), as well as an ability to make effectively targeted referrals."

Does Halbert's observation apply to other libraries? Along the continuum from specialization to integration, different libraries may settle at different points as their optimal configurations. The choice is usually an outcome of a number of considerations, including the management structure of the commons, physical layout of the facilities, human resources as well as funding available. Nevertheless, whatever solution a library adopts, staff recruitment and training are always crucial to the service effectiveness and quality.

What level of personnel can provide an optimal level of service at a commons environment? What kinds of skills and knowledge are they expected to have? What composes the "additional knowledge broadly applicable to new technology" in Halbert's comment? Investigations into technology-related questions received at libraries should help to find answers.

Libraries accumulated decades of experience in handling reference questions; however, little is known about the nature of technology-related questions that users ask in the new commons environment. A good understanding of the content of these questions, the types of assistance users seek and the complexity of fielding these questions would be crucial for libraries to define reference service in terms of service goals, staffing level and staff competency, and to plan targeted training program for effective frontline service.

\section{Study Questions}

This study looked at 1,636 transactions at the Information Commons Help Desk of the Hong Kong University of Science and Technology Library (HKUST Library) to answer these questions:

1. What kinds of assistance do users seek from the Help Desk?

2. How complex is it to handle the technology questions?

3. What are the key competencies desirable of the Help Desk staff? 
The primary objective of the study is to construct a profile of the technology questions for planning staffing and paraprofessional training at the HKUST Library. The results would also inform libraries and commons staffing in other institutions. Moreover, commons managers may apply the taxonomy developed in this study for their local analysis.

\section{Literature Review}

There are many studies and discussions of reference services in the new technology environment. Some explore the staffing model and configuration of service points after a commons is introduced; some focus on training programs for paraprofessionals; a few investigate reference questions samples to help determine staffing level. However, rarely do they focus on technology transactions.

\section{Service models and staffing in a commons environment}

A combination of professional librarians and highly trained computer specialists provides the highest quality service; however, in reality, the best arrangement possible within available resources is usually deploying properly trained paraprofessionals or student helpers. MacWhinnie finds that most of the commons she examined either combine some level of professional staffing with student workers or limit the amount of professional staffing to hours of peak use. ${ }^{2}$

When the Atkins Library at the University of North Carolina at Charlotte implemented an information commons, a new Combined Services Desk operated in parallel with the Reference Desk on a different floor. Moving towards a "tiered" reference model, a training program was developed for paraprofessionals at the combined desk to assist students accessing and using databases. ${ }^{3}$

Dallis and Walters review reference service changes in the commons environment at the Indiana University-Bloomington. Under the partnership between the library and the university IT unit, the three IC service points are operated by expertise from both sides. While student technology consultants shoulder the technology support duty, reference staff focus their energy on reference questions. Although the 
number of reference transactions decreased, library staff found that the questions became more advanced and required more discussion. ${ }^{4}$

A study at the University of Massachusetts Amherst's W.E.B. Du Bois Library evaluated the specialiststaffed Reference Desk as part of a suite of expert services provided in a Learning Commons. In such serviceintensive environment, specialization succeeds because of collaborative communication, training, and referral. $^{5}$

At the service desk of the Information Center at the University of Montana-Missoula Mansfield Library, three levels of support were put in place to address the increase in technical support queries: student workers, reference technicians and librarians. Training was composed of a two-week series and on-going continuous education. Central to the model is a team of personnel committed to quality service and, in particular, to the success of the IC; and underscoring this team concept is the need for successful training and a competent referral system. ${ }^{6}$

In a 1997 paper, McLean describes how library staff at Macquarie University was trained to work on the IT Desk. ${ }^{7}$ Although the technology has changed since 1997, the key competencies he listed for his institution may be generalized and rephrased in modern terms as:

- Understanding of what constitutes quality customer service

- Ability to analyse questions and identify customer need

- General knowledge of databases available in the library

- Knowledge of Internet applications

- Knowledge and understanding of the key operational practices of the computing services in the library and the university

- Knowledge of setting up internet connection

- Knowledge of Windows operation 
Boyd reviews staffing issues at commons. Various libraries have come up with competencies-based rubrics for commons staff. Similar to McLean's list, they include information literacy and service skills in addition to technology competencies. ${ }^{8}$

\section{Reference questions logging}

In order to establish appropriate staffing level, the University of Arizona Library studied logged questions at a few service points. The study team looked at the kind of question and the level of employee needed to answer it based upon existing training. They found that students and trained generalists could answer over $95 \%$ of the questions asked at each service point. ${ }^{9}$

In the study to assess the cost-effectiveness of staffing a traditional academic reference desk, Ryan designed categories to differentiate questions that could be answered by a trained staff member as opposed to a librarian. Over 6,000 transactions were analyzed, $12.4 \%$ was categorized as "Technology". Ryan noted that "[W]hile a few technology questions could be considered complicated (creating formulas in Excel, for example), most concerned printing, downloading, identifying drives, network connections, logins, passwords, and other issues unique to the library's particular workstation configurations." ${ }^{10}$

A study of questions received at the service desk closest to the front door of Texas A\&M University's Evans Library was conducted to establish appropriate staffing models, develop relevant training and plan service desk. ${ }^{11}$ The transactions were sorted according to the correctness of the answers and what the users were seeking. Results showed that $10.7 \%$ were computer-related questions.

Driven by the needs for triage and training at a new single service desk, Warner introduced a new classification system that bases on the skills and strategies requirement to address questions. ${ }^{12}$ Henry and Neville tested Warner's system and the traditional Katz's system that categorizes by reference resources. They found that, as library resources included so many electronic and technological items, Warner's "skills" approach was more relevant and applicable than the Katz's "reference" approach. ${ }^{13}$ Meserve et. al. adopted the Warner's model as an effective tools for analyzing reference services. ${ }^{14}$ 
These studies demonstrate a variety of approaches to analyzing reference question logs, which are recorded differently at different libraries. The emergence of the Warner's model may help to provide certain standard to future practice and study.

\section{Methodology}

\section{Context of the study}

The Hong Kong University of Science and Technology (HKUST) is one of the three major research universities in Hong Kong. In 2008/09 academic year, there was an enrollment of over 9,000 students and close to 500 teaching staff. Postgraduates represent $36 \%$ of the student body, with the rest $64 \%$ being undergraduates. Comprising of four Schools: Science, Engineering, Business, Humanities and Social Science, HKUST attracts high caliber students from Hong Kong, Mainland China and other countries. The School of Science ( $20 \%$ of the student body) offers programs emphasizing areas of technological importance. The School of Engineering (39\% of the student body) is strong in both teaching and research. The School of Business ( $36 \%$ of the student body) is recognized as one of the best in the area; it has been consistently ranked among the top business schools in Asia and Australia. The School of Humanities and Social Science ( $5 \%$ of the student body) balances students development by offering undergraduate minor programs and postgraduate degree programs. One can therefore expect that HKUST students are in general proficient in computer applications and comfortable with using technology in their learning.

The Library launched its Information Commons (IC) in September 2006 as a pilot project. At Spring Semester 2009, the IC core area located on the entrance floor of the Library provided 50 computers, networked printing and scanning facilities. Two presentation rooms equipped with ceiling-mount data projectors and wireless keyboards were located on lower floors. Software at the IC included Microsoft Office, SPSS, graphic software such as PaintShop Pro and Macromedia suite, and a myriad of web authoring tools. The Library building provides wireless internet connection, and the use of notebook computers is very popular among users. The IC Help Desk, serviced by two full time IC Officers and a team of student helpers, 
provided technical assistance to IC users. All IC team members are graduates or students of computer programs. The Help Desk faced the IC area, with the Reference and Information Counter in close proximity. It opened 69 hours a week during the semesters. Owing to the physical layout, it was very obvious that the IC Help Desk was the point for technical assistance on using the IC facilities. Most transactions recorded were about technology rather than informational.

The Library was expanding the IC in Fall Semester 2009. Improvements included an increase in computer count, enriched scanning and printing facilities, more varieties of study space, as well as a wider spectrum of service. At the same time, the service desks were redesigned, and the service model was to be revised with the plan of deploying paraprofessionals at this technology service point. As a preparation for the recruitment and training of a new Help Desk team, the author carried out this study of Help Desk transaction analysis in the summer 2009.

\section{The sample}

Since the opening of the IC in 2006, Help Desk staff was instructed to record all transactions electronically using a program that was modified locally from the open source software LibStats. From the opening of the IC on September 12, 2006 to May 30, 2009, 4,312 transactions were recorded.

For this study, the author formed a sample by extracting transactions recorded between the $7^{\text {th }}$ and $13^{\text {th }}$ (roughly the second week of the month) and between the $18^{\text {th }}$ and $24^{\text {th }}$ (roughly the third week of the month) from Jan 2007 to May 2009. After excluding transactions there were not recorded clearly enough to be analyzed, the sample contains 1,636 transactions. The records were first categorized by Question Types in order to identify the technology questions, which were then further analyzed with a focus on complexity, using the multi-faceted taxonomy developed in this study.

\section{Question types}

Traditionally, libraries classify reference questions by types such as "ready reference", "directional", "referral", etc. Classification in reference services must be used with caution because it defines discrete 
categories where experience finds process and continuity. ${ }^{15}$ The same is valid for service transactions of technology nature.

When assigning Question Types, the author looked at the primary services users needed help on, rather than what resources library staff employed to field the questions. For instance, a transaction to help a student printing a PDF document would be assigned as "Printing" rather than "Computing", while helping a student editing a PDF document would be categorized as "Computing".

After looking through the sample, the author identified these Question Types:

Technology types:

- Computing: questions about hardware and software at the IC

- Printing: all questions and troubleshooting relating to printing

- Scanning: all questions and troubleshooting relating to scanning

- Photocopying: all questions and troubleshooting relating to copying

Non-technology types:

- Library Resources: questions about the use and access of library resources

- Service: questions on general services and policies

- Information: informational questions and questions that do not fit into the other categories

The technology types were further analyzed to explore their complexity.

\section{Complexity}

There seems to be no established method of evaluating how complex or difficult reference transactions are in the library profession. A survey suggested that only $11 \%$ of libraries collected data on the difficulty of the question. ${ }^{16}$ Robinson developed a conceptual framework and a vocabulary which can be used to discuss strategies and choices involved in reference question handling. He also defined the concepts of simple and 
complex questions and answers, and level of difficulty in handling a reference question. ${ }^{17}$ However, the discussion has limited applicability to technology questions.

The concept of the Warner's model that categorizes questions based on the skill level of the answers offers certain applicability. However, the author found that a single-dimension categorization is insufficient for this study. A multi-faceted approach was therefore developed to analyze the technology questions.

\section{Facet 1. Technical level}

There is no objective measure for how technical a question is. Bearing in mind that a primary purpose of the study was to inform the design of the training program, the author focused on whether the skills and knowledge to comprehend and answer a question is readily acquirable via targeted training program within a library. She, being an experienced reference librarian with reasonable level of computer literacy, defined two tiers of technical level:

Tier 1 - areas manageable by a computer-literate person without formal technical background. These are questions that can be effectively answered by all personnel after well-planned training. At the HKUST environment, Tier 1 covers basic Windows operations such as file management, common Microsoft Office operation, PDF files editing.

Tier 2 - areas that call for computer knowledge beyond general computer literacy. At the HKUST environment, these are questions that involve computing terms, programming, less frequently enquired software, software installation that requires administration login, and computer setting.

By analyzing the Tier 1 transactions, the author identified a set of specific technical competencies that are supposed to be transferrable to paraprofessionals via carefully designed training program.

To other libraries, what skills are categorized as Tier 1 or Tier 2 would vary from institution to institution. Nevertheless, the concept of defining the "trainable areas" for staff can provide guidance to the subsequent design of staffing and training program. 


\section{Facet 2. Troubleshooting}

One dimension of transaction complexity is the degree of analysis required to effectively help the users. While delving into the cognitive process of a technology transaction is beyond the scope of this study, whether the questions fall into the troubleshooting type would be an indicator of the demand for analysis. In troubleshooting transactions, users find hardware or software not functioning as they expected; staff needs to perform diagnosis to find out the causes of the problems. Analytical skills become a must in these circumstances. Although it is far from a comprehensive measure of the cognitive requirement, the proportion of troubleshooting transactions provides a baseline for the complexity of the process.

\section{Facet 3. Answer types}

Inspired by the Warner's classification model, this facet approaches the complexity of the transactions by looking at the answers. Compared to informational and reference questions, technology questions fall within a foreseeable scope. A high proportion of them is limited to the computing services and facilities provided within the library; in a way, they can be reasonably anticipated. This pattern of such "foreseeable questions" can be revealed by the answers in the sample. Accordingly, the author identified four types of answers, with ascending level of complexity:

Level A- Direct answer: These are simple, verbal answer to questions about services and facilities; no demonstration is required.

Level B- Skill-based demonstration for foreseeable questions: These demonstrations are simple and controllable. Examples include "how to print a document", and "how to count the number of words in a document".

Level C- Strategy-based demonstration for foreseeable questions: These demonstrations or operations involve strategy or complex steps in the demonstration; often more than one option may be possible to field the question. Examples include "setting up the wifi connection at a user's notebook", and "how to convert a PDF table into an Excel table". 
Level D- Others: they are mostly answers for questions that are not commonly raised, or questions that are beyond frequent usage of the software and facilities; staff has very few or no precedent cases for reference.

\section{Results and discussion}

\section{Question types (1,636 transactions)}

Table 1: Question Types

\begin{tabular}{|c|c|c|c|}
\hline & & $\begin{array}{c}\text { No. of } \\
\text { questions }\end{array}$ & $\%$ \\
\hline \multicolumn{4}{|c|}{ Technology Types } \\
\hline & Printing & 660 & $40.3 \%$ \\
\hline & Computing & 592 & $36.2 \%$ \\
\hline & Copying & 38 & $2.3 \%$ \\
\hline & Scanning & 122 & $7.5 \%$ \\
\hline \multicolumn{4}{|c|}{ Non-technology Types } \\
\hline & Services & 148 & $9.0 \%$ \\
\hline & Information & 42 & $2.6 \%$ \\
\hline & $\begin{array}{l}\text { Library } \\
\text { resources }\end{array}$ & 35 & $2.1 \%$ \\
\hline Total & & 1,636 & $100 \%$ \\
\hline
\end{tabular}




\section{Major sub-groups}

The percentage in this section is presented with respect to the sample size 1,636 . For easy reference, one percentage point represents roughly 16 transactions.

\section{Printing}

- Giving printing instruction: $20.3 \%$

- Printing troubleshoot: $10.5 \%$

\section{Computing}

- Wifi setting at users' laptops: $10.9 \%$

- Software operation (including Microsoft Office, Adobe PDF and others): $8 \%$

- PCs (login, logout, basic operation): $3.8 \%$

- Peripherals (USB, mouse, earphones and handwriting pad): $2.4 \%$

- Web and email: $2.4 \%$

- Policy and service on computing facilities: $1.9 \%$

- Monitor problems: $1.8 \%$

- Viewing, reading, writing CDs and DVDs: $1.3 \%$

\section{Scanning}

- Scanner operation: $4.8 \%$

- Miscellaneous scanning questions: $2.6 \%$

\section{Services}

- Lost and found: $5.5 \%$

- Stationery: $2.3 \%$

\section{Information}

- University online service: $1.2 \%$

\section{Library Resources}

- Access and use the book and media collection: $1.4 \%$ 
Table 1 and Table 2 show that the dominating Question Types are Printing, Computing (Wifi setting) and Computing (Software operation). Technology questions (Printing, Computing, Scanning, Copying) summed up to $86.3 \%$ of the sample.

Although the Reference and Information Counter was within close proximity of the IC Help Desk, 13.7\% of the questions handled at the Help Desk were non-technology types. While most of "Services" types were directional and policy questions, a good portion of the "Information" and "Library Resources" types should have been referred to reference librarians. The profile revealed here indicated the importance of an effective referral system among different service points.

\section{Complexity of technology subset (1,411 transactions)}

The findings here addressed Study Question 2: "How complex is it to handle the technology questions?"

\section{Facet 1: Technical complexity}

In terms of technical complexity, about $82 \%$ belong to Tier 1 . In another word, $82 \%$ of the technology questions are expected to be handled effectively by paraprofessionals after training.

Table 3: Techical complexity in two tiers

\begin{tabular}{|l||l|l|}
\hline & No. of questions & $\%$ \\
\hline Tier 1 & 1,163 & $82.4 \%$ \\
\hline Tier 2 & 248 & $17.6 \%$ \\
\hline Total & 1,411 & $100 \%$ \\
\hline
\end{tabular}

\section{Facet 2: Troubleshooting}

Table 4 shows that more than one-third of the questions were coded as Troubleshooting types, for which staff needs to apply analytical skills to perform diagnosis. However, it is necessary to emphasize that these are not the only questions that call for analytical skills. This proportion is indicative, but is not intended to be a comprehensive measure of skill requirement. 
Table 4: Proportion of Troubleshooting transactions

\begin{tabular}{|l||c|c|}
\hline & No. of questions & $\%$ \\
\hline Non-troubleshooting & 933 & $66.1 \%$ \\
\hline Troubleshooting & 478 & $33.9 \%$ \\
\hline Total & 1,411 & $100 \%$ \\
\hline
\end{tabular}

\section{Facet 3: Answer types}

In terms of the skill level of the answers, "Level A- direct answer" makes up $14.5 \%$ of the sample. Almost half of the sample falls into "Level B- skilled-based demonstration for foreseeable questions". Another $29 \%$ belongs to "Level C- strategy-based demonstration for foreseeable questions". This indicates that, if the Library builds a knowledge base of answers for these foreseeable questions, close to $80 \%$ the questions can be fielded with consistency and quality. Fewer than $7 \%$ of the cases were unexpected or unfamiliar questions.

Table 5: Answer Types in four levels

\begin{tabular}{|l||l|l|}
\hline & No. of questions & $\%$ \\
\hline Level A & 205 & $14.5 \%$ \\
\hline Level B & 701 & $49.7 \%$ \\
\hline Level C & 410 & $29.1 \%$ \\
\hline Level D & 95 & $6.7 \%$ \\
\hline Total & 1,411 & $100 \%$ \\
\hline
\end{tabular}

\section{Key Competencies}

To address Study Question 3: "what are the key competencies desirable of the Help Desk staff?", the author went through the content of the questions, the analysis required to find the answers, and the types of answers. The exercise identified the technical skills and knowledge desirable, and the service skills required for effective diagnosis of technical situation.

\section{Technical competencies}

This list of technical competencies is the result of going through the Tier 1 technology questions. Some skills are specific to the IC environment at the HKUST Library. The list indicates core areas for a training program, and will evolve following changes in users' needs and technology. 
- Understanding of service scope and access policy of the commons

Staff is clear about what software is available at the IC, and common software that is NOT provided at the IC; they are familiar with the rules and policies at the IC such as users' files location, access right, etc.

- Knowledge on Windows operations

Staff knows how to use different drives, including USB and external hard drives; they are able to adjust Windows settings, control desktops, perform screen captures, etc.

- Ability to handle common hardware situation

This includes sorting out problems with peripheral and cable connections at the PCs, and performing PC reboots wisely. In the HKUST Library context, this area also covers helping users login IC workstations using HKUST SmartCard, and setting the wireless keyboard for the Presentation Rooms.

- Understanding of the Printing system

Staff efficiently monitors and manages the network printing system to maintain smooth operation; they know how to clear paper jam, refill paper and toner, sort out trouble with the payment card reader, and help users adjust print setting at different software applications.

\section{- Proficiency in performing Scanning}

This includes scanner operation, scanning software setting, and OCR processing.

\section{- Knowledge in Microsoft office applications}


This covers common operations of Word, Excel and PowerPoint, including but not limited to file saving and conversion, content relocating among various Microsoft files and PDF files, images creating and handling in Microsoft operations, page and content formatting, etc.

- Knowledge on using Internet and Browsers

Staff knows about different types of browsers, how to change browser setting, such as character encoding, cookies, history, etc. They are able to ftp files, save web page content into various file formats, and assist users in using the HKUST WebMail application.

- Knowledge on setting wireless network connection

Staff has a clear picture of the service scope of the wireless connection for notebook users in the library; they can assist different types of users to perform standard setting under common operating systems.

- Knowledge on PDF creation and editing

- Knowledge of writing and using CDs and DVDs

This covers how to handle DVDs of different regions, differentiate video DVDs and data DVDs, and understand the implications of the types.

\section{- Fluency in handling Chinese characters inputting software}

Staff may not need to be fluent in the inputting skills, but should know how to switch between different inputting options, perform conversion between simplified and traditional characters, and understand the limitations of the conversion.

\section{- Ability to handle multimedia files}


Staff knows what software users can use for creating audio and video files at the IC and the basic operation; they understand the types and functioning of different audio and video files and players, how to transfer files and convert between file types.

- Ability to handle graphic files

Staff knows about different graphic file formats, and how to perform simple graphic manipulation using basic tools such as IrfanView and Paint.Net .

\section{- Ability to zip and unzip files}

\section{Service skills}

Similar to librarians performing effective reference interview, personnel handling technology questions also need to demonstrate good communication skills to understand the users' real questions. Although technology questions are generally easier to express than information needs, staff's attitude to listening is still important to ensure effective communication. Specific in handling technology situation is the willingness and efficiency of conducting diagnosis. The study identified one-third of the sample transactions as Troubleshooting type; yet any question that starts as a direct, simple one may evolve into another that calls for further evaluation. Therefore, it is essential that help desk staff should be:

- willing to initiate diagnosis

- able to analyze situations to identify the cause of problems

- capable of evaluating resources and knowledge required to answer questions

- able to distinguish when a question should be referred to a reference librarian or an technician

\section{The importance of referrals}

From users' point of view, the differentiation of reference, informational and technology questions has little meaning; they direct their questions to the most convenient or welcoming service points instead of the designated ones defined by libraries. A robust referral system becomes instrumental. Targeted referrals 
may take place from paraprofessionals and student workers to technicians or librarians, or between technicians and librarians. Libraries must carefully determine and document when and how referrals should be done. Morgan lists several approaches a library can take when reference questions should be referred to librarians: $:^{18}$

- define a set of frequently asked questions for paraprofessionals; all other queries should be referred to librarians

- create a list of core resources that paraprofessionals should be familiar with; if a question cannot be answered using a listed source, a referral should be made

- compile a list of tasks that are deemed manageable by paraprofessionals

- using an agreed time frame, if a staff member realizes that answering the question will take longer than that, he or she will refer the user to a professional

These approaches are equally applicable for technology questions; although different criteria would be necessary for references and technology questions. Libraries should also consider different referral procedures for the two types of questions. Compared to informational questions, technology questions have a stronger sense of immediacy. Making smooth and efficient referrals without straining library staffing or arousing unpleasant feeling on users' side requires careful deliberation.

\section{Conclusion}

This study shows that librarians and paraprofessionals who have gone through well-designed training programs can provide robust support to $82 \%$ of technology questions received at a modern library with an information commons like the HKUST Library. With the help of a knowledge base, staff can handle close to $80 \%$ of the transactions with consistent efficiency and quality.

Besides the set of technical competencies identified by the study, information and service skills are also essential. Competencies requirement of different groups of staff, intertwined with the design of the referral 
systems, forms a central component for service planning. In such a complex service and information environment as a commons in an academic library, no one can answer all questions from users. Referral is therefore a critical element in quality service delivery. Whether a library has various service points or an integrated one, staff should be able to make good judgment about when and how a referral should be made, and whom the user should be referred to. This relates back to staffing model and staff competencies.

This study results guided the HKUST Library in moving from a specialized technology help desk model towards a more integrated model where one paraprofessional or IC officer pairs up with a librarian. The competencies identified formed the core content of the technology component of the training, which was further supplemented with a library skills component for the IC officers. In addition, a mechanism was being constructed to build and maintain a collective knowledge base for staff's perusal as well as continuous training.

Technology continues to shape reference service in libraries. Ever since libraries incorporated collections in electronic format, librarians have been coping with users' needing technical help in accessing the resources, from operating CD-ROMs, downloading files from networked servers, to resolving remote access issues such as proxy and cookie setting. The new wave of technology questions at service points brought about by the "commons" can be viewed as an extension of this trend. With a good understanding of the technology questions users raise, an effective training program can be derived. With a wellmaintained infrastructure for the team to share a common knowledge base, a clearly documented list of staff competencies, and an efficient referral system, libraries are well-equipped to deliver quality service in this new and ever changing technology environment. 
${ }^{1}$ Martin Halbert, "Lessons from the information commons frontier," The Journal of Academic Librarianship 25 (March 1999): 90-91.

${ }^{2}$ Laurie A. MacWhinnie, "The information commons: the academic library of the future," portal: Libraries and the Academy 3 (April 2003): 241-257.

${ }^{3}$ Frada Mozenter, Bridgette T. Sanders, and Carol Bellamy, "Perspectives on cross-training public service staff in the electronic age: I have to learn to do what?!" The Journal of Academic Librarianship 29 (6) (November 2003): 399-404.

${ }^{4}$ Diane Dallis and Carolyn Walters, "Reference services in the commons environment," Reference Services Review 34(2) (2006): 248-260.

${ }^{5}$ Elizabeth B. Fitzpatrick, Anne C. Moore, and Beth W. Lang, "Reference librarians at the reference desk in a learning commons: a mixed methods evaluation," The Journal of Academic Librarianship 34(3) (May 2008): 231-238.

${ }^{6}$ Sue Samson and Erling Oelz, "The academic library as a full-service information center," The Journal of Academic Librarianship 31(4) (July 2005): 347-351.

${ }^{7}$ Neil McLean, “Convergence of libraries and computing services: implications for reference services," LASIE 28(3) (September 1997): 5-9.

${ }^{8}$ Robert Boyd, "Staffing the commons: job analysis in the context of an information commons," Library Hi Tech 26(2) (2008): 232-243.

${ }^{9}$ Marianne Stowell Bracke et. al., "Finding information in a new landscape: developing new service and staffing models for mediated information services," College \& Research Libraries 68(3) (May 2007): 248-267. 
${ }^{10}$ Susan M. Ryan, "Reference transactions analysis: the cost-effectiveness of staffing a traditional academic reference desk," The Journal of Academic Librarianship 34(5) (September 2008): 389-399.

${ }^{11}$ Pixey Anne Mosley, "Assessing user interactions at the desk nearest the front door," Reference \& User Services Quarterly 47(2) (Winter 2007): 159-167.

${ }^{12}$ Debra G. Warner, "A new classification for Reference Statistics," Reference \& User Services Quarterly 41 (Fall 2001): 51-55.

${ }^{13}$ Deborah B. Henry and Tina M. Neville, "Testing classification systems for reference questions," Reference \& User Services Quarterly 47(4) (2008): 364-373.

${ }^{14}$ Harry C. Meserve, Sandra E. Belanger, Joan Bowlby and Lisa Rosenblum, "Developing a model for reference research statistics: applying the 'Warner Model' of reference questions classification to streamline research services," Reference \& User Services Quarterly 48(3): 247-258.

${ }^{15}$ Jo Bell Whitlatch, "Question classification," in The Reference Assessment Manual (Ann Arbor, Mich.: Pierian, 1995), 42-46.

${ }^{16}$ Eric Novotny, Reference Services Statistics \& Assessment: A SPEC Kit. (Washington, D.C.: Association of Research Libraries, 2002.)

${ }^{17}$ Barbara M. Robinson, "Reference services: a model of question handling," RQ 29 (Fall 1989): 48-61.

${ }^{18}$ Pamela J. Morgan, Training paraprofessionals for reference service: a how-to-do-it manual for librarians (New York: Neal-Schuman Publishers, Inc., 2009): 19. 